International Journal of Engineering \& Technology, $7(4)(2018) 2122-2126$
International Journal of Engineering \& Technology
SPC
Website: www.sciencepubco.com/index.php/IJET
doi: $10.14419 /$ ijet.v7it.13508
Research paper

\title{
Evaluating the performance and efficiency of MPPT algorithm for PV systems
}

\author{
Adnan Hussein Ali ${ }^{1}{ }^{*}$, Ali Abdulwahhab Abdulrazzaq ${ }^{1}$ \\ ${ }^{1}$ Middle Technical University, Technical Instructors Training Institute, Baghdad, Iraq \\ *Corresponding author E-mail: aaddnnaann63@gmail.com
}

\begin{abstract}
Solar photovoltaic (PV) systems have an advantage of conversion sun's energy to electrical energy without regulation and lower efficiency due to I-V nonlinear characteristics that exhibits in the PV cells. Essentially, There is a need to maximize power extraction from these cells with a maximum power point tracking (MPPT) techniques. The performance of MPPT Algorithm involves a presentation of the PV system model with a most suitable method, Perturbation and Observation (P\&O). The P\&O implementation is done by MATLAB simulating, which covers a PV cell connected to a controlled buck converter by MPPT algorithms. The achievement of the P\&O algorithm with a higher efficiency as well as be able to fast MPP tracking at the Constant irradiation condition as well as with variable irradiation.
\end{abstract}

Keywords: PV system; Maximum Power Point Tracking (MPPT); Perturb and Observe (P\&O) Algorithm.

\section{Introduction}

The Photovoltaic (PV) solar system has an application of Maximum power point tracking (MPPT) technique to maximize a power conversion at any conditions as well as wind turbines. This PV system occurs in various configurations with respect to their connection to inverter schemes, external grids, battery banks, in addition to other electrical loads [1]

The PV panels can be considered as a good source of electrical power, so that, their efficiency of conversion could not considered high. The conversion of sunlight energy with PV strength to electrical power may be comparatively imperfect, with conversion efficiency typically in the $12 \sim 20 \%$ range, this range could drop more over panel temperature adjustable, change of solar irradiation in addition to load conditions [2]. Furthermore the dependence of the total energy generated usefully on environmental features such as solar irradiance and surrounding temperatures. So that, the control unit for achieving maximum power from the output of PV panels need an appropriate approach for the MPPT technique to be qualified for providing a suitable duty cycle for DC-DC converter.

The definitive destination of the solar power can't be problem at any case, so, the MPPT essential problem deals with the efficiency of power transfer of solar cell depend on sunlight amount which drops on the solar panels in addition to the characteristics of electrical load, changes in amount of sunlight leads to change in the load characteristics that give high power transfer efficiency, hence system efficiency optimization is accomplished if a change occurs in the load characteristics for preservation of the power transfer at maximum efficiency [3]. A load characteristic is referred as maximum power point and the process of discovering such point be considered MPPT that saves the load characteristics there. The MPPT system essentially comprises two fundamental elements, a switching power (DC-DC converter) accompanied by control algorithm of an MPPT for operating a PV system so that to transfer to the load a maximum accomplishing power. MPPT con- siders an electronic device which introduces between a PV panel and the load as seen in Fig. 1-a [4]. MPPT devices may be generally integrating into converter power system that provides both voltage and current regulation, conversion, and filtering to drive different loads, involving power grids, charging batteries, or motors [5].

\section{MPPT simple system}

It is very important to power system operates at the high power efficiency with PV generation by approving that, it is working at maximum power continuously anyway of varying loads in addition to weather environments. An MPPT-PV stand-alone power system typically contains of the PV array, load and DC/DC converter (Buck, Boost) switching (step-up, down), that performs as a powerful interfacing between the PV modules and the load as shown in figure $1-b$.

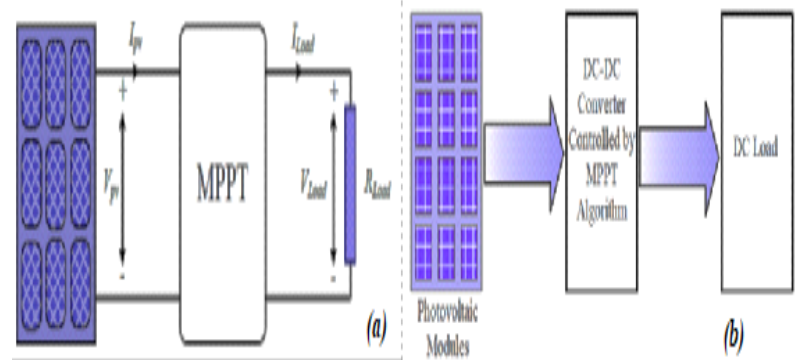

Fig. 1: MPPT-PV- A) MPP Tracker B) Proposed System.

If a connection of load is directly to the solar panel, then rarely an operating point of the panel will be at maximum power. The impedance which seen by the panel will drive the solar panel's operating point. Therefore, by varying this impedance, the operating point may be moved to peak point. Since panels are DC devices, there must be utilizing of DC-DC converters for transforming the 
impedance of one circuit to the other load. By varying the DC-DC converter duty ratio results in changing an impedance that of the panel. The panel (I-V) curve can significantly vary with atmospheric conditions variation like temperature and radiance. Thus, it is not practical the duty ratio to be fixed with these dynamically moving operating conditions [7].

\section{Characteristics of PV system}

Several models had been established for describing the currentvoltage (I-V) characteristics of solar cells with various operating conditions. The single-diode and double-diode models are a commonly represented by the behavior of a solar cell [8].

The PV panel is constituted by a PV set cells fixed serially and parallel for generating a normal maximum electrical power that depends on the conversion efficiency of semiconductor photoenergy organizing the cells. A PV cell may be considered like a generator of a photo-current $\mathrm{I}_{\mathrm{ph}}$ relying on external factors such as working temperature or direction of the panel. PV cells are currently denoted by the one-diode model, figure $2-\mathrm{a}$ as well as a double-diode model, figure 2-b, in which are also represented the various parameters of the model [8].

The one diode model equation of describing currents is

Icell $=$ Ipv $=$ Iph - ID - ISH

The supplied current $\mathrm{I}_{\mathrm{ph}}$ by the cell is

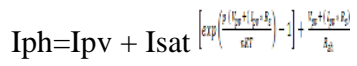

The double diodes of the PV panel model are shown in figure 2-b. Subsequently, the output current $\mathrm{I}_{\text {cell }}$ can be denoted by

Icell $=$ Iph - Id $1-$ Id $2-$ Ish

Where $\mathrm{I}_{\mathrm{ph}}$ is the light incident generated current from the panel. Also, the diffusion current through the diodes $I_{d 1}$, recombination mechanisms current Id2, and Ish, the current through Rsh which represents the panel loss, are given in Equation (4) [9].

Id $1=$ Isi $\left[\exp \left(\frac{\left(V_{C e n l}+\left(I_{c e l l}^{*} R_{s}\right.\right.}{n i * V t}\right)-1\right]$

For $\mathrm{i}=1,2$

$\mathrm{Ish}=\left(\frac{\left(V_{\mathrm{Cell}}+\left(I_{\mathrm{Cell}} R^{*} R_{s}\right.\right.}{R s h}\right)$

Where $\mathrm{I}_{\mathrm{si}}$ is the diodes reverse saturation current, the diode's ideality factor is ni, and the thermal voltage $\mathrm{Vt}=\mathrm{k} / \mathrm{Tq}$ the of the panel.

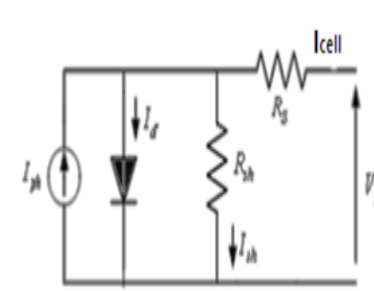

(a)

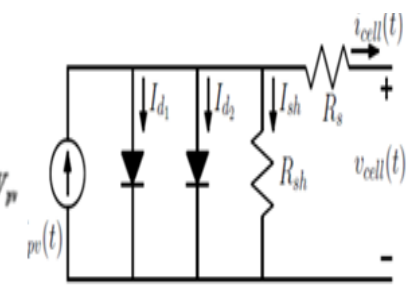

(b)
Fig. 2: A) PV Cell Equivalent Circuit B) PV Panel, Double-Diode Model.

\section{Circuit topology \& DC-DC converter oper- ation}

\subsection{Solar array}

For a component of solar array, a model of the array is produced which is depend on diode equation:

$$
\mathrm{Id}=\mathrm{Isat}(\mathrm{eqVd} / \mathrm{kT}-1)
$$

where $I_{d}$ is the diode current $(A), V_{d}$ is the diode voltage $(V)$. For our simulation, a solar array that could output greater than $100 \mathrm{~W}$ of power was selected. This panel has characteristics of $\mathrm{V}_{\mathrm{oc}}$ of $22 \mathrm{~V}$ with Isc of $8.4 \mathrm{~A}$. The voltage at maximum power $\mathrm{Vmp}$ is $17.5 \mathrm{~V}$ while the current at maximum power Imp is 7.7A. By plugging these values into the $\mathrm{P}=\mathrm{IV}, 135 \mathrm{~W}$ can be achieved $\mathrm{P}$ out from the solar array at full solar illumination.

If the incident illumination of the PV solar array is varying in addition to the output resistance, A Power versus Voltage and Current versus Voltage graphs can be extracted to find the MPP of the solar array, as shown in figure 3. The MPP is the peak of the Power versus Voltage graph.
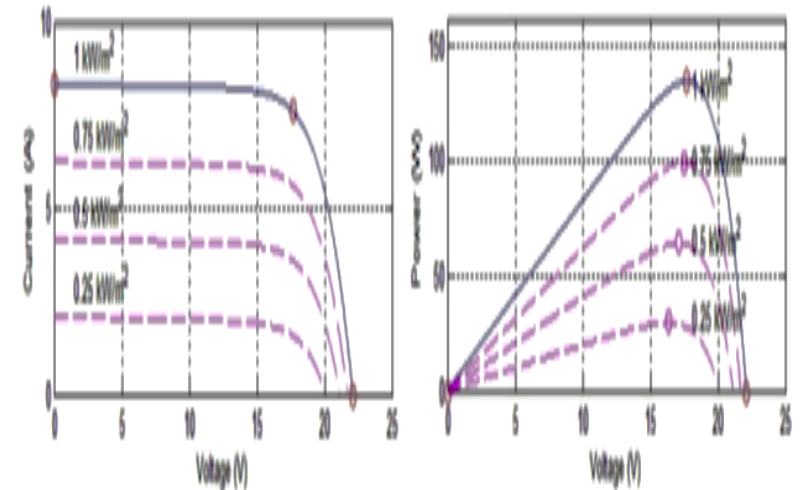

Fig. 3: Power Vs Voltage \& Current vs Voltage Graghs from PV Panel Model.

\subsection{Perturb and observe (P\&O) algorithm}

Many MPPT algorithms have been designed and implemented in MATLB SIMULINK. The used algorithm is the improved perturb and observe (IP\&O) technique. The simulation test of the IP\&O has been done in the system by using a resistive load for verifying its improvement in comparison with the conventional $\mathrm{P} \& \mathrm{O}$ technique. The $\mathrm{P} \& \mathrm{O}$ algorithm for finding the MPP is commonly utilized in commercial applications. This technique employs current and voltage sensors for measuring the output of a solar array. The $\mathrm{P} \& \mathrm{O}$ algorithm can be considered the easy and cheapest in implementation, generally, due to its dependence on passive component circuits to evaluate the voltage and current. MPPT algorithm desires such measurements that are the only outside data sources to control whether increasing or decreasing the duty cycle D. A comparison has been made between input power with that of a former input power which measured so as to control if to change the duty cycle for continuing tracking the MPP [10].

The $\mathrm{P} \& \mathrm{O}$ algorithm inspects the previously calculated input power with any change of the duty cycle, which happened in a specified period of time. Now, if the recently measured input power has a greater value than the previously measured input power besides the new input voltage has a greater value than the old input voltage, $\mathrm{P} \& \mathrm{O}$ algorithm has decreased $\mathrm{D}$ to move closer to the peak power. Otherwise, when the input voltage has less value than previously calculated then this algorithm will increase D if greater input power exists [11]. Another condition when a new measuring power with less value than formerly measured besides the new voltage with greater values than the old one, $\mathrm{D}$ will be decreased for convergent to an MPP. In conclusion, when the power and voltage are less valuable than formerly measured, then $\mathrm{D}$ will be decreased by $\mathrm{P} \& \mathrm{O}$ algorithm, all these can be described by a flow chart in fig 4. 


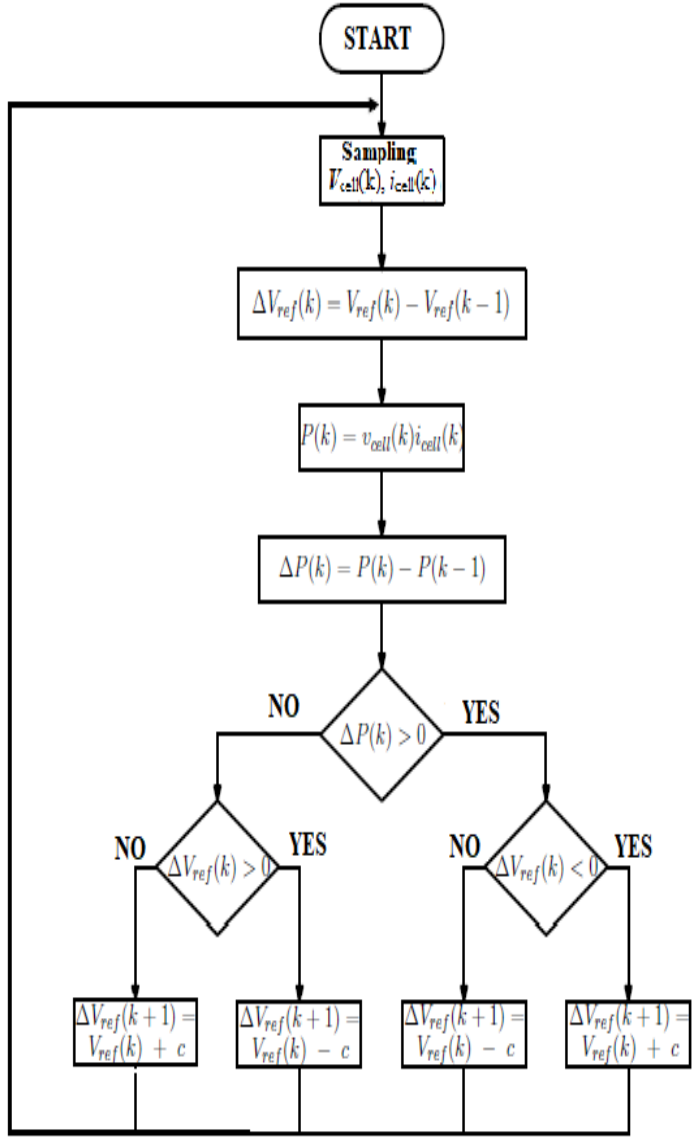

Fig. 3: Flow Chart of $\mathrm{P} \& \mathrm{O}$ Algorithm.

\subsection{Buck converter}

The buck converter is considered as a switched mode power supply, which means it offers digital control by PWM of a switch and results in a linear response in output voltage. Buck converter contains two switches, a diode and transistors, in addition to an inductor for continually maintaining a voltage on the output capacitor. It is commonly used in a too high level input voltage and desires to be lowered to suitable levels. The principle of buck converter is a step down converter which produces an output voltage with lower average values than the $\mathrm{DC}$ input voltage $\mathrm{V}_{\mathrm{d}}$. Its application mainly focuses in regulated DC power supplies as well as DC motor speed control as explained in figure 5 [12].
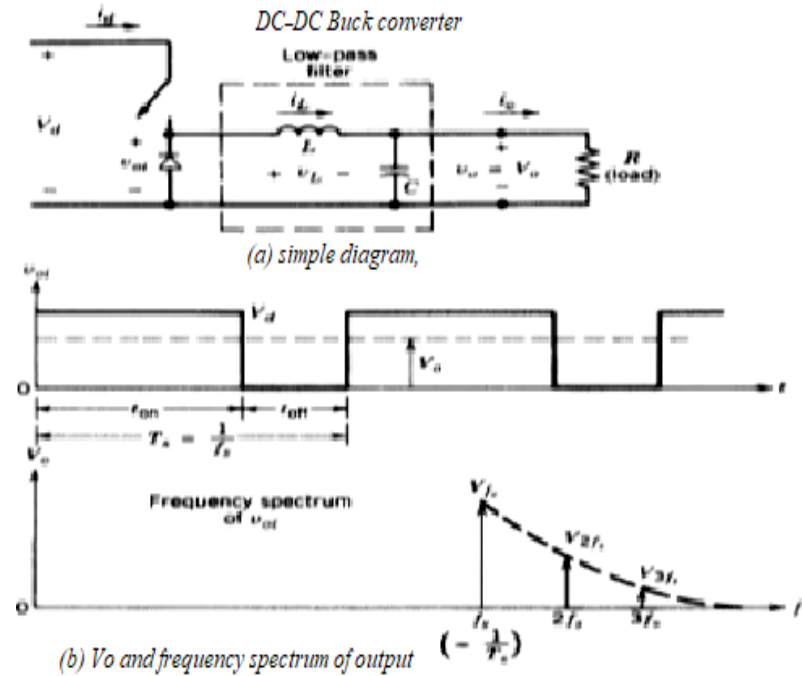

Fig. 5: DC-DC Buck Converter A) Simple Diagram, B) Vo and Frequency Spectrum of Output.

The $\mathrm{V}_{\text {oi }}$ waveform shown in part (b) is represented as a function of switch position. This $\mathrm{V}_{\text {oi }}$ waveform is the switching output that indicates the input to the low-pass filter in part (a). The average output voltage can be calculated in terms of switch's D using $\mathrm{Vo}_{\mathrm{o}}=$

$\frac{1}{T s} \int_{0}^{N_{0}} V_{0}(t) d t=\frac{1}{T_{l}} \int_{0}^{t o n} V_{d}(t) d t+\int_{\text {ton }}^{T_{s}} 0 d t=\frac{t_{\text {on }}}{T_{s}} V_{d}=D V_{d}$

where, Vo is the DC output voltage, with switching period Ts, $\mathrm{v}_{\mathrm{o}}(\mathrm{t})$ is the instantaneous output voltage as a function of time, ton is the on duration of the switch per switching period, and $\mathrm{V}_{\mathrm{d}}$ represents DC input voltage.

\subsection{Load}

Active load Simulation is very complex, so that in order for optimizing the buck converter besides MPPT algorithm through simulation, a using of resistive load which remains constant during each test. The Duty cycle D of the buck converter can be adjusted by an MPPT controller to match the MPP of the array, thus, optimizing output power. The efficiency assessment of the buck converter can be made by exploring the output voltage.

\section{Simulation results $\&$ discussion}

\subsection{Power efficiency}

In order to estimate the power efficiency ( $\eta$ ), the maximum power must be wanted to know under the given circumstances which the solar array may produce. From integrating the measuring output power and the maximum power, the MPPT efficiency (nMPPT) can be calculated by

$$
\eta \mathrm{MPPT}=\frac{\int_{0}^{T s} \text { pout }(t) d t}{P_{\max }(t) d t}
$$

The output waveforms are comparing from each run to achieve a greater thoughtful about how $\mathrm{P} \& \mathrm{O}$ algorithm reacts to different changes in solar array irradiance. Any changes in the temperature or in the irradiation immediately lead a change of the available power, inducing a displacement of the operating point from the maximum power point, which has for significance a degradation of the efficiency of the considered PV system, also notice that the controllers of MPPT are very sensitive with these variations.

\section{2. $P \& O$ algorithm at constant irradiance}

This is a first simulation run that used an input to the solar array with constant irradiance by MATLAB model. The input voltage shows an obtaining the steady state value after $1 \mathrm{msec}$, while the input current oscillates quite a few till the constant amount, the input power has the same behaviour of voltage and current as it deals with them, as illustrated in fig. 6 which has the efficiency of constant irradiance. The output voltage indicates an amount of ripple at a response curve, which can be measurable, whereas the output current displays small overshoot at the initial response before MPPT controlling, then a PWM of the gate which is controlled by MPPT fetch it closer to the MPP, as shown in fig. 7 which also contains the output power that could be remained constant after 2 msec onward due to a above constant MPP voltage and current. Finally, with regard to the efficiency of the converter, it can be seen that it reaches a steady state of $95 \%$ shortly after 1 msec and furthermore it remains almost totally flat to the end of the simulation time. 

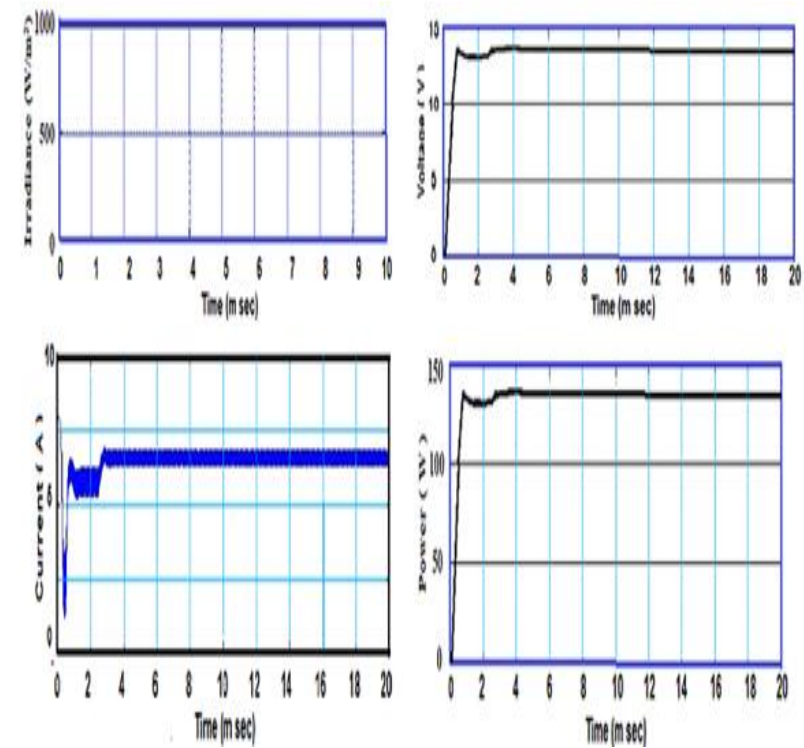

Fig. 6: Irradiance and Input Sources of Voltage, Current, and Power at Constant Irradiation.
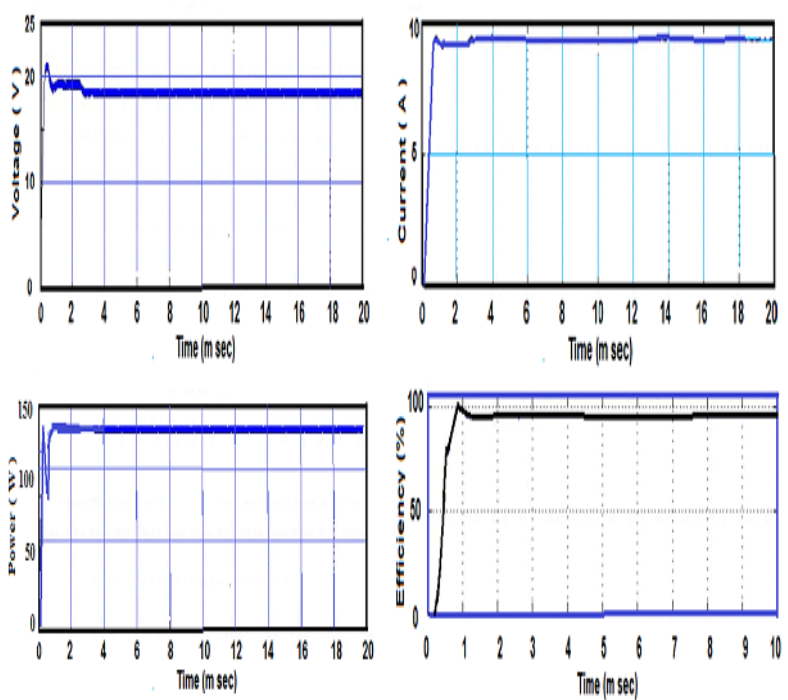

Fig. 7: Efficiency and Output Voltage, Current, and Power at Constant Irradiation

\subsection{P \& O with variable irradiance}

The second stage includes a run of the MATLAB model via an input of variable irradiance to the solar array. The changes in irradiance are tracked by both the source and output voltage, current, and power. Figure 8 displays the source voltage which changes with the irradiance steps, while the current response shows a little start-up overshoot occurs with every change in irradiance, during the operation, there was a tendency of the source current oscillating a bit If the MPPT controller was in operation, and finally the input power is a result of voltage and current responses.

Figure 9 shows the output response for all parameters, the efficiency of the converter shot to over $100 \%$; this caused a little slow down in the input power. Normally, it can be said that despite the sudden changes in irradiance, the efficiency did not go below $80 \%$ as illustrated in figure $9-a$, the output voltage, current, and power follows the input sources for tracking the input irradiance changes, In comparison to the input power, the output power remains relatively close in magnitude.
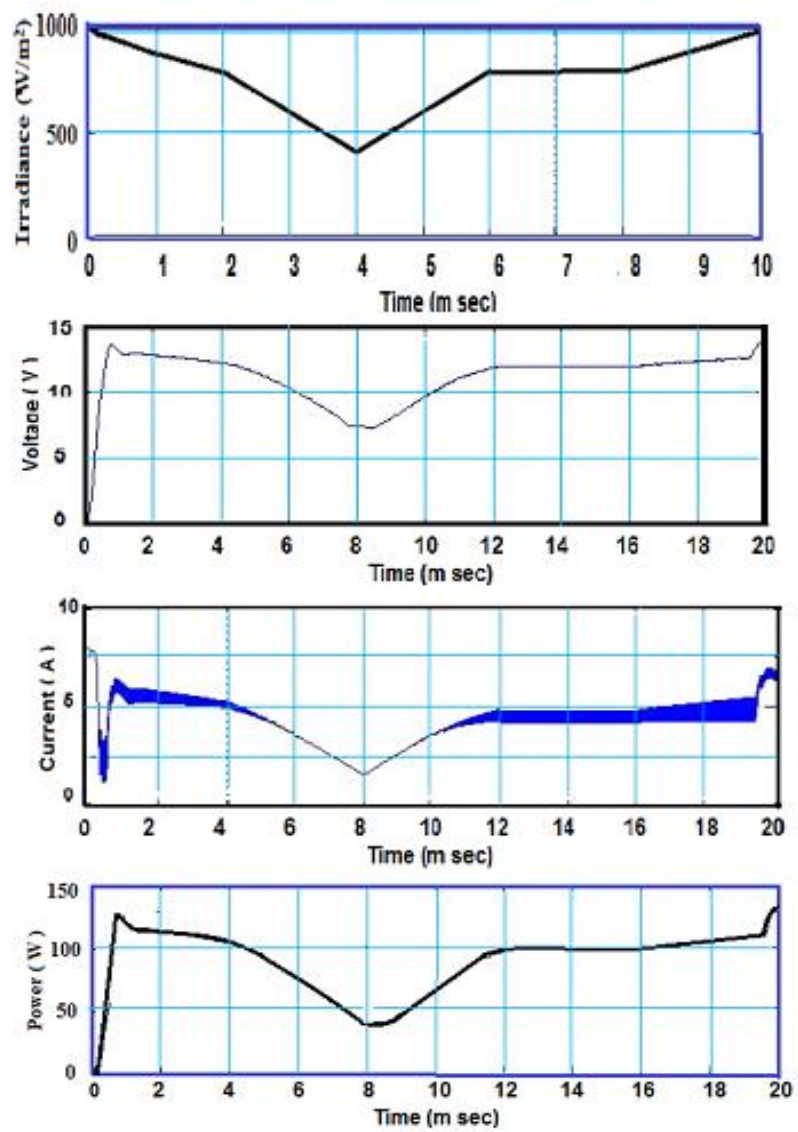

Fig. 8: Irradiance and Input Sources of Voltage, Current, and Power.
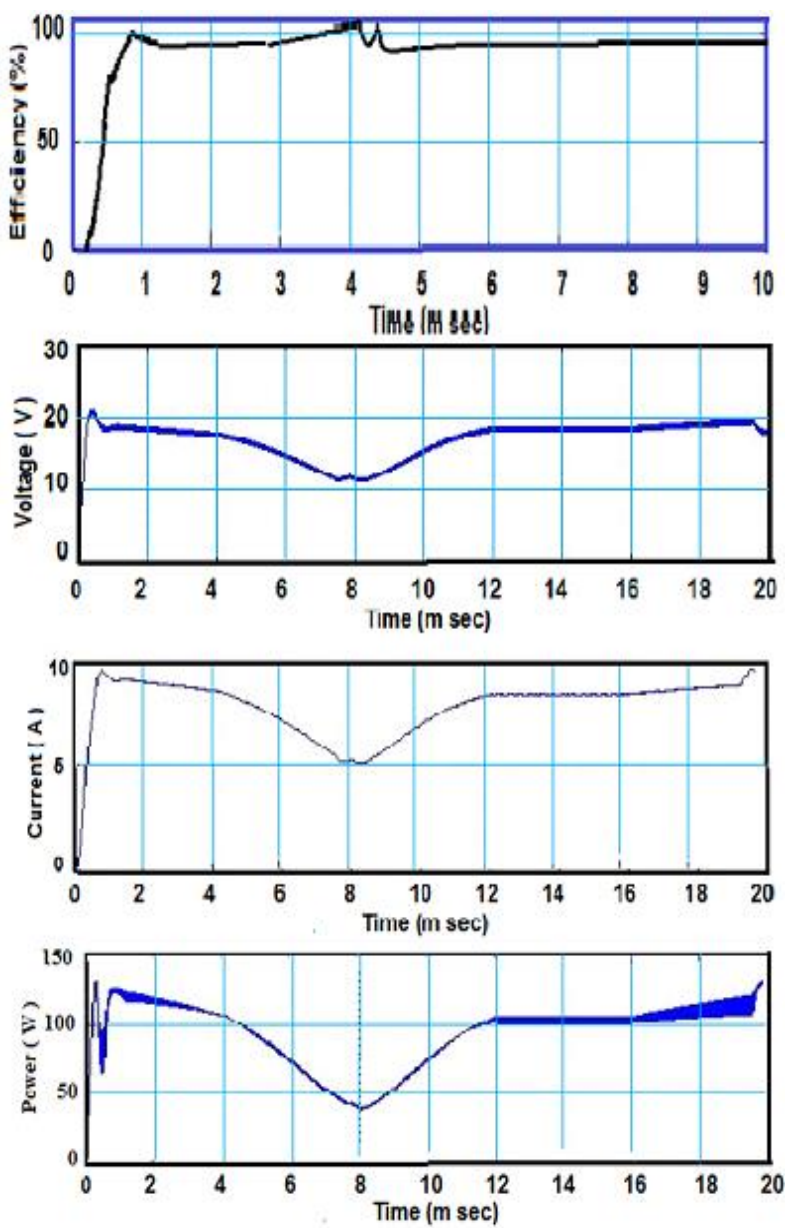

Fig. 9: Efficiency and Output Voltage, Current, and Power. 


\section{Conclusion}

A comparative simulation of MPPT algorithm had been executed in this paper, at first, a brief presentation of the chief components of a PV system in addition to explaining the principle of circuit operation of DC-DC Converters. Simulation was implemented with MATLAB-Simulink environments. The efficiency simulation of the P\&O Algorithm of the converter was done by two cases, the first run with Constant Irradiance and second with input of variable irradiance. The actual data gathering runs were done in firs run included the $\mathrm{P} \& \mathrm{O}$ algorithm with a constant irradiance of $1000 \mathrm{~W} / \mathrm{m}^{2}$, and then with a random variable of irradiance to the solar array. Generally, the outcome tests of the $\mathrm{P} \& \mathrm{O}$ algorithm can be believed quite good. As this algorithm may be optimized to face requirements of certain timing, its response is faster and can be performed better compared with other algorithm.

\section{References}

[1] L. Atik, , P. Petit, J. P. Sawicki, Z. T. Ternifi, G. Bachir,"Comparison of four MPPT techniques for PV systems", AIP Conference Proceedings 1758, $030047 \quad$ (2016); https://doi.org/10.1063/1.4959443.

[2] D. Verman, S. Nela, A.M. Shandilya, Soubhagya, K. Dash ' Maximum power point tracking (MPPT) techniques: Recapitulation in solar photovoltaic systems' ELSEVIER, Renewable and Sustainable Energy Reviews, February 2016, Volume 54, Pages 1018-1034. https://doi.org/10.1016/j.rser.2015.10.068.

[3] M Seyedmahmoudian, B Horan, R. Rahmani, A. Maung, Efficien Photovoltaic System Maximum Power Point Tracking Using a New Technique, $\quad$ Energies 2016, 9, 147; https://doi.org/10.3390/en9030147.

[4] A. Tobón, J. Peláez-Restrepo, Juan P. Villegas-Ceballos, S. SernaGarcés, Maximum Power Point Tracking of Photovoltaic Panels by Using Improved Pattern Search Methods Energies 2017, 10, 1316, https://doi.org/10.3390/en10091316.
[5] A. J. Abid1, F. M. Al-Naima, and Adnan H. Ali, Comprehensive Modeling of Photovoltaic Array based on Proteus Software, IJAER (2018), Volume 13, Number 6 pp. 4440-4447.

[6] H. Islam, S. Mekhilef, N. Binti Mohamed Shah, T.K. Soon, M. Seyedmahmousian, Performance Evaluation of Maximum Power Point Tracking Approaches and Photovoltaic Systems, Energies 2018, 11, 365; https://doi.org/10.3390/en11020365.

[7] Karami, N.; Moubayed, N.; Outbib, R. General Review and classification of different (MPPT) Techniques. Renew. Sustain. Energy Rev. 2017, 68, 1-18. https://doi.org/10.1016/j.rser.2016.09.132.

[8] Seyedmahmoudian, M.; Horan, B.; Soon, T.K.; Rahmani, R.; Oo, A.M.T.; Mekhilef, S.; Stojcevski, A. State of the art artificial intelligence-based MPPT techniques for mitigating partial shading effects on PV systems, A review. Renew. Sustain. Energy Rev. 2016 64, 435-455. https://doi.org/10.1016/j.rser.2016.06.053

[9] Soon, T.K.; Mekhilef, S. A fast-converging MPPT technique for photovoltaic system under fast-varying solar irradiation and load resistance. IEEE Trans. Ind. Inform. 2015 11, 176-186. https://doi.org/10.1109/TII.2014.2378231.

[10] Deshpande, A.; Patil, S.; Deopare, H. Comparative simulation of conventional maximum power point tracking methods. In Proceedings of the 2016 International Conference on Computing, Communication and Automation (ICCCA), Noida, India, 29-30 April 2016 pp. 1025-1028. https://doi.org/10.1109/CCAA.2016.7813867.

[11] Kollimalla, S.K.; Mishra, M.K. A novel adaptive P\&O MPPT algorithm considering sudden changes in the irradiance. IEEE Trans. Energy Convers.2014, 29, 602-610 https://doi.org/10.1109/TEC.2014.2320930.

[12] Saravanan, S. Babu, N.R. Performance analysis of boost \& Cuk converter in MPPT based PV system. In Proceedings of the 2015 International Conference on Circuit, Power and Computing Technologies (ICCPCT), Nagercoil, India, 19-20 March 2015; pp. 1-6. https://doi.org/10.1109/ICCPCT.2015.7159425. 